\title{
How to Perform Safe Anesthesia in Patients with End-Stage Renal Disease
}

\section{Christian Seidl • Balthasar Eberle}

University Department for Anesthesiology and Pain Therapy, Inselspital, Bern University Hospital, Bern, Switzerland

\begin{abstract}
Vascular surgical patients and especially those with end-stage renal disease are exposed to a high risk of preventable adverse events. Typically, a combination of organizational and technical deficiencies, human error or ineptitude and patient comorbidity leads to inadvertently poor outcome. Patient safety in perioperative environments requires permanent effort in organizational improvement, staff training, and maintenance of high standards in patient care and technical equipment. Even in multimorbid patients, anesthesia for vascular access surgery can be performed at low to moderate risk if safety problems are minimized.

(c) 2015 S. Karger AG, Basel
\end{abstract}

\section{Recommendations to Improve Patient Safety}

- Preoperative preparation for anesthesia should identify individual risks and areas for optimization. An interdisciplinary perioperative plan should be developed and communicated to the entire team.

- Institutionalized surgical safety checks and OR safety precautions help to reduce and manage unexpected adverse events.

- Locoregional anesthesia offers, as an advantage, transient regional sympathectomy and blood flow enhancement without cardiopulmonary depression. General anesthesia avoids interaction with anticoagulant regimes and allows, if required, extension of surgery. Local anesthesia may require supportive sedation and monitoring. 
- The use of 2-D ultrasound imaging and guidance is state of the art for vessel cannulation and nerve blocks.

- Proficiency and teamwork of the providers appear more important than anesthesia technique itself, but typical risks and complications need to be anticipated.

\section{Preoperative Evaluation and Planning}

Patients requiring vascular access surgery are frequently multimorbid, and surgery is often nonelective. Efficient preoperative planning requires communication of accurate data, dates and details of schedules and procedures. This includes planned location and type of vascular access, patient preparation and positioning, use of grafts or distal perfusion, etc.

Practice guidelines and standard operating procedures of each service should be available. Documentation of individual perioperative surgical requirements should precede clinical evaluation by anesthesiology.

Responsibilities for management of chronic and preoperative medication need to be clearly defined and communicated between all involved caregivers. Timely prescription (e.g. treatment of preoperative anemia), reliable continuation (e.g. beta-blockers, aspirin, statins) [2], timely discontinuation (e.g. metformin, platelet inhibitors, new oral anticoagulants), and effective bridging (insulin, unfractionated heparin) of preoperative medications increase patient safety by reducing risks of myocardial ischemia, bleeding and transfusion, and help to avoid case cancellations.

Preanesthetic evaluation assesses the patient's physical status (American Society of Anesthesiologists ASA PS; table 1) [3] according to relevant active comorbidity, medical, surgical and anesthetic history. Results of diagnostic testing are reviewed, and a focused physical exam is obtained [4]. Factors with relevant impact on perioperative management are identified.

The overall aim is to predict a patient's tolerance to the perioperative stress of his/her specific surgical procedure. Whereas peripheral reconstructive vascular surgery carries a particularly high risk of perioperative cardiac morbidity and mortality, peripheral vascular access surgery is classified as low or moderate risk surgery.

Impaired kidney function is a robust indicator of increased perioperative risk. Patients with end-stage renal disease (ESRD) requiring vascular access surgery are thus usually ASA class 3 or 4, related to their overall health status. ASA classification does not take surgical risk into consideration; this needs to be categorized separately using appropriate scoring systems [5]. 
Table 1. Anesthesiologic risk classification for the determination of perioperative risk and quick estimation of physical fitness using MET values [6]

\begin{tabular}{|c|c|}
\hline \multicolumn{2}{|c|}{ ASA physical status classification } \\
\hline ASA 1 & Normal healthy patient \\
\hline ASA 2 & Patient with mild systemic disease \\
\hline ASA 3 & Patient with severe systemic disease \\
\hline ASA 4 & Severe systemic disease that is a constant threat to life \\
\hline ASA 5 & Moribund patient who is not expected to survive without the operation \\
\hline ASA 6 & Declared brain-dead patient (organ donor) \\
\hline \multicolumn{2}{|c|}{ Essential MET values } \\
\hline $1-3 \mathrm{MET}$ & $\begin{array}{l}\text { Walking around in the flat, taking care of oneself (eating, getting dressed, } \\
\text { cleaning) }\end{array}$ \\
\hline 4-6 MET & $\begin{array}{l}\text { Climbing more than one flight of stairs without stopping, walking }>100 \mathrm{~m} \\
\text { on plain ground, easy homework }\end{array}$ \\
\hline$\geq 10 \mathrm{MET}$ & Sports activities (tennis, swimming, football, skiing) \\
\hline
\end{tabular}

Preoperative assessment of coronary status and cardiovascular function is based on clinical evaluation, noninvasive and invasive diagnostic testing. Physical performance is evaluated according to simple exercise tasks (e.g. walking up stairs), and is quantified by grading their metabolic equivalent (MET, table 1). At a performance of $4 \mathrm{MET}$ or more, the patient is usually fit for vascular access surgery in locoregional anesthesia (LRA) without further cardiac evaluation [6].

If MET cannot be evaluated, the presence of clinical risk factors (renal dysfunction, ischemic heart disease, congestive heart failure, stroke or TIA, diabetes mellitus requiring insulin) is relevant. If up to 2 risk factors are present, noninvasive testing may be considered, but only if it will change management. If 3 or more risk factors are present, cardiology consultation and further cardiac testing are considered.

In patients with a cardiac implantable electrical device (CIED), such as an internal cardiac pacemaker or defibrillator (ICD), some basic information needs to be gathered preoperatively (e.g. indication, current mode of action, underlying cardiac rhythm, type and model of device, accessibility by cardiologist, response to magnetic influence, last function control).

Clinical assessment of pulmonary status is based on history, auscultation and noninvasive pulse oximetry/arterial blood gas analysis on room air. Chest radiography and spirometry are indicated only in patients with known or suspected significant pulmonary disease. Chronic pleural effusion may require preoperative drainage to support respiratory compensation of renal acidosis, the more so if sedation is planned. Current medication regimens should be optimized. 
In preexisting severe or acutely exacerbated lung disease, expert pulmonology consultation should be obtained. Radiological imaging, body plethysmography and CO diffusion capacity are indicated only if results would substantially influence perioperative management.

Patients with moderate to severe pulmonary disease requiring vascular access surgery will benefit most from a LRA technique. General anesthesia (GA) with intermittent positive pressure ventilation (IPPV) and use of muscle relaxants impairs respiration more than LRA with maintained spontaneous breathing. IPPV may cause dynamic overinflation or barotrauma to lungs, promote atelectasis and impair mucociliary clearance [7]. This may be associated with increased pulmonary morbidity, prolonged hospital stay, resource utilization and cost.

Questions of specific anesthetic interest in a patient's history should address allergies [e.g. to local anesthetics (LA), antibiotics, disinfectants, radiocontrast, protamine]. Previous experiences with general and LRA, the risk of postoperative nausea and vomiting, chronic steroid medication and relevant substance abuse should be explored. Substitution therapy may be necessary.

Proactive patient blood management implies pre-, intra- and postoperative issues. Timely preoperative conventional or noninvasive hemoglobin testing should be routine in order to allow anemia workup and treatment. Anemia associated with ESRD should be treated appropriately in advance of elective surgery. If indicated, hematopoietic stimulation with recombinant erythropoietin and concomitant iron substitution should be instituted to avoid or minimize perioperative allogeneic transfusion as well as related immunomodulation, infection and cost. This is particularly important in patients awaiting renal transplantation. Nevertheless, type and screen should be available in any patient undergoing vascular access surgery.

Screening for coagulation disorders or impairment, as well as for active anticoagulant and/or antiplatelet medication relies first on history and physical exam. Preoperatively, pertinent conditions and medications must be meticulously reviewed. Focused laboratory testing should follow only if indicated (INR, aPTT, fibrinogen level, platelet count; platelet function testing; thromboelastometry).

Adequate orders for discontinuation, bridging or timing of anticoagulants must be written to avoid interference with the planned surgery and LRA, but also in order to avoid thromboembolic complications [8]. In patients with recently stented coronaries, mechanical valves or chronic atrial fibrillation, a cardiology consult should be obtained.

The most common substances that are suitable in patients with renal insufficiency are listed in table 2, together with pertinent lab tests and recommended 
Table 2. Widely used anticoagulants and their safe perioperative management [8]

\begin{tabular}{|c|c|c|c|c|c|c|c|c|}
\hline \multirow{2}{*}{$\begin{array}{l}\text { Mode of } \\
\text { action }\end{array}$} & \multirow[t]{2}{*}{ Antagonist } & \multirow[t]{2}{*}{ Lab test } & \multirow[t]{2}{*}{ Substance } & \multicolumn{3}{|l|}{ Stop prior to } & \multirow[t]{2}{*}{ Bridging } & \multirow{2}{*}{$\begin{array}{l}\text { Pause } \\
\text { after } \\
\text { operation }\end{array}$} \\
\hline & & & & operation & $\begin{array}{l}\text { single-shot } \\
\text { regional block }\end{array}$ & GA & & \\
\hline $\begin{array}{l}\text { COX } 1 \\
\text { inhibition }\end{array}$ & $\begin{array}{l}\text { no } \\
\text { specific }\end{array}$ & $\begin{array}{l}\text { platelet } \\
\text { function } \\
\text { test }\end{array}$ & ASS & $\begin{array}{l}\text { continue - } \\
\text { stop may } \\
\text { be harmful }\end{array}$ & $\begin{array}{l}\text { continue - } \\
\text { stop may } \\
\text { be harmful }\end{array}$ & no & no & no \\
\hline $\begin{array}{l}\text { ADP } \\
\text { receptor } \\
\text { blocker }\end{array}$ & $\begin{array}{l}\text { no } \\
\text { specific }\end{array}$ & $\begin{array}{l}\text { platelet } \\
\text { function } \\
\text { test }\end{array}$ & $\begin{array}{l}\text { clopidogrel } \\
\text { prasugrel } \\
\text { ticagrelor }\end{array}$ & $\begin{array}{l}7 \text { days } \\
7-10 \text { days } \\
5 \text { days }\end{array}$ & $\begin{array}{l}7 \text { days } \\
7-10 \text { days } \\
5 \text { days }\end{array}$ & no & no & no \\
\hline $\begin{array}{l}\text { Xa } \\
\text { antagonist }\end{array}$ & $\begin{array}{l}\text { no } \\
\text { specific }\end{array}$ & $\begin{array}{l}\mathrm{F} \text { Xa } \\
\text { activity }\end{array}$ & $\begin{array}{l}\text { apixaban } \\
\text { rivaroxaban }\end{array}$ & $\begin{array}{l}2 \text { days } \\
1-2 \text { days }\end{array}$ & $\begin{array}{l}2 \text { days } \\
1-2 \text { days }\end{array}$ & no & heparin & no \\
\hline $\begin{array}{l}\text { Vitamin K } \\
\text { antagonist }\end{array}$ & vitamin $\mathrm{K}$ & INR & coumadin & $\begin{array}{l}\text { stop assure } \\
\text { INR }<1.4\end{array}$ & $\begin{array}{l}\text { stop assure } \\
\text { INR }<1.4\end{array}$ & no & heparin & $\begin{array}{l}\text { continue or } \\
\text { bridging }\end{array}$ \\
\hline $\begin{array}{l}\text { AT III } \\
\text { activator }\end{array}$ & protamin & $\begin{array}{l}\text { aPTT/Xa } \\
\text { activity }\end{array}$ & heparin & $4-6 h$ & $4-6 h$ & no & no & at least $1 \mathrm{~h}$ \\
\hline $\begin{array}{l}\text { Prostaglandin } \\
\text { inhibition }\end{array}$ & $\begin{array}{l}\text { no } \\
\text { specific }\end{array}$ & $\begin{array}{l}\text { platelet } \\
\text { aggrega- } \\
\text { tion test }\end{array}$ & $\begin{array}{l}\text { iloprost } \\
\text { prostacyclin }\end{array}$ & $\begin{array}{l}2 \mathrm{~h} \\
0.5 \mathrm{~h}\end{array}$ & $\begin{array}{l}2 \mathrm{~h} \\
0.5 \mathrm{~h}\end{array}$ & no & no & no \\
\hline
\end{tabular}

ASS $=$ Acetylsalicylic acid

discontinuation intervals. The field of anticoagulant and antiplatelet medication is evolving rapidly. Practitioners may benefit from guideline-based smartphone applications (e.g. CoaguSafe ${ }^{\circledR}$ for iPhone ${ }^{\circledR}$ ) to support clinical judgment when balancing risks of bleeding and thrombosis.

Preoperative serum electrolyte status should be known in patients with ESRD. Hemodialysis is indicated prior to surgery, if relevant hyperkalemia (6.0 $\mathrm{mEq} / \mathrm{l}$ or more) is present, to protect the patient from life-threatening arrhythmia. Severely abnormal serum sodium or chloride needs further workup and slow correction. In emergencies, electrolyte correction is initiated without delaying life-saving surgery.

In insulin-dependent diabetics, presurgical fasting and possible delays in the OR schedule may complicate blood glucose management, and will require close blood glucose and insulin control. Perioperative glucose control is recommended in the range of $100-180 \mathrm{mg} / \mathrm{dl}$ or $5.6-10.0 \mathrm{mmol} / \mathrm{l}$ to decrease complications (e.g. wound infections) without running risks of hypoglycemia and stroke.

Patient and nursing team information about smoking, food and drink restrictions as well as preoperative medication is mandatory. Smoking should be stopped at least $24 \mathrm{~h}$ prior to the operation to enhance tracheal clearance. Fasting is recommended for a minimum of $6 \mathrm{~h}$ prior to anesthesia for food and $2 \mathrm{~h}$ for clear liquids [9]. 
Pharmacological premedication is usually prescribed for patients with planned overnight hospital stay. Low-dose benzodiazepines provide anxiolysis, light sedation and anterograde amnesia. Especially at advanced age, benzodiazepines may elicit paradoxical reactions or predispose to postoperative delirium. Alternatives for oral premedication are clonidin or haloperidol. Ambulatory patients usually do not receive preoperative sedatives.

\section{Preoperative Safety Precautions}

Good interdisciplinary communication between surgeon and anesthesiologist minimizes delays and cancellations in the schedule and helps to prevent or anticipate critical situations. Charts and records should be made accessible to all perioperative caregivers. Ideally, they should review scheduled patients together in advance.

Anesthesia must be clearly informed of surgical positioning, access or cannulation sites in order to plan their monitoring and instrumentation. If necessary, postoperative hemodialysis, intermediate or intensive care should be organized at this time.

At this point, the decision about the planned anesthesia technique (e.g. GA, regional block, local anesthesia with or without sedation) and monitoring must be made by the anesthesiologist in accordance with surgical requirements and with the patient's informed consent.

Throughout the preoperative and preincision periods, a Surgical Safety Checklist should be completed according to the standardized, structured threetiered 'Team Time Out' process recommended by the World Health Organization [10]. All steps are documented in the patient's record.

Part 1: Prior to transfer to the OR, the patient is personally identified and the surgeon marks the site of surgery. A hospital-wide implemented patient identification bracelet with patient name, date of birth and identification number ensures correct patient verification.

Part 2: Prior to anesthesia induction, the patient is identified again by name and birth date, which are compared with ID bracelet and records. The scheduled surgical procedure is confirmed by the patient, and the surgical site marking by the OR staff. A brief review of patient's written informed consent, allergies, fasting interval, airway anatomy, ordered antibiotic prophylaxis, availability of blood products and readiness of anesthesia equipment is completed. Specifically in these patients, preoperative information is verified on correct medication intake, on fluid restriction orders, the interval since last hemodialysis and residual urinary output. 
Part 3: Immediately prior to incision, the entire OR team performs a team time-out. Team members briefly introduce themselves and their role. The surgeon explains the procedure; the anesthetist mentions any special concerns. The team rehearses conceivable critical situations and their prospective management. Antibiotic administration and the availability of special surgical and anesthesia equipment are confirmed.

Special attention in such patients focuses on the presence and function of preexisting arteriovenous fistulae, hemodialysis central venous catheters, or access for peritoneal dialysis. Arms with vascular accesses are kept free from blood pressure cuffs, pulse oximeters, tourniquets and peripheral venous cannulae.

Gastric emptying is delayed in chronic renal failure [11] or diabetes, which presumptively increases the risk of regurgitation and pulmonary aspiration of gastric contents on induction of GA or during deep sedation. $\mathrm{pH}$ of gastric secretions can be raised by oral administration of sodium tricitrate $(30 \mathrm{ml}, 0.3$ $\mathrm{mol} / \mathrm{l}$ ) within $1 \mathrm{~h}$ of induction. Also, peritoneal dialysate liquid should be drained from the peritoneal cavity prior to OR transfer and induction of anesthesia. If GA is planned, precautions for rapid airway control on induction should be taken.

If perioperative antibiotic prophylaxis is indicated, responsibility for drug choice, timing and administration must be clear to all. Typical antibiotics for perioperative prophylaxis in vascular surgery target bacterial colonization at the surgical site, such as cephalosporin (e.g. cefazoline, cefuroxime). To achieve adequate tissue concentration, a time interval between i.v. administration and skin incision of 30-60 min is mandatory. The dose of a single shot antibiotic prophylaxis is not adapted to renal clearance, but repetition doses may require adaptation.

Life-threatening allergic responses to medication are rare, with antibiotics, relaxants, latex and colloid infusions as the main culprits. Preoperative team awareness of known allergies can avoid most major incidents. Minor reactions such as skin rash, pruritus or wheals may remain the only manifestation (class I), requiring symptomatic treatment only. As first or co-manifestation, lifethreatening symptoms like oropharyngeal swelling, bronchospasm, hypotension, or shock may ensue (class II-IV). Such symptoms are a clear indication for adrenalin (100 $\mu \mathrm{g}$ i.v. bolus), with repetition as needed until the situation improves. In patients without anticoagulation, $0.3-0.5 \mathrm{mg}$ of adrenalin can be given intramuscularly to provide a continued effect [12]. Exposure to all suspected agents is stopped immediately, $100 \%$ oxygen is given, and additional help (resuscitation team) is called for.

LA intoxication from inadvertent intravascular injection or rapid systemic absorption of a large LA dose manifests itself by acute changes in CNS function 
(dysesthesia, drowsiness, tremor, generalized convulsions). This may be followed by myocardial depression and bradyasystole or ventricular fibrillation. Such incidents require immediate institution of Basic and Advanced Life Support, and an attempt to attenuate toxic LA action by a trial of Lipid Rescue Therapy (Intralipid ${ }^{\circledR} 20 \% 1.5 \mathrm{ml} / \mathrm{kg}$ i.v., repeatable to a maximum of $8 \mathrm{ml} / \mathrm{kg}$ ) [13]. Ropivacaine appears less cardiotoxic than bupivacaine and may thus be preferable in patients with cardiovascular comorbidity. Prilocaine can cause significant methemoglobinemia, making it a poor choice in an anemia-prone population.

An increasing number of patients present for vascular access surgery carrying a CIED (e.g. internal pacemaker, defibrillator ICD, or cardiac resynchronization therapy) [14]. In these patients, the surgeon needs to brief the team ahead of time about the use of electrocautery. If monopolar cautery is needed, the pathway of the cautery current should be directed far away from the CIED, and the device should be reprogrammed or deactivated temporarily. Depending on the device and indication, the pacemaker function may be adjusted to a reasonable rate and mode of action [15].

Line placement for monitoring and medication in peripheral or central venous or arterial locations is often challenging. Numerous previous surgeries, preexisting fistulae, failed cannulation attempts, hematoma, venous collapse after hemodialysis, thrombotic vessel occlusion or the presence of CIEDs in central veins reduce options and prolong preparation time.

Frequently, central line or venous dialysis catheter placement under residual anticoagulation cannot be avoided. Ultrasound guidance of vessel puncture and cannulation facilitates line placement and reduces complication rate (futile punctures, hematoma, accidental arterial puncture and injection, nerve damage). Use of ultrasound imaging to guide central venous catheter insertion has been recommended as a measure to improve patient safety by national health care guideline organizations (www.ahrq.gov 2001; www.nice.org.uk 2002). Central venous catheterization (CVC) requires full barrier precautions (mask, cap, scrubbing, sterile gown and gloves, sterile equipment handling) to reduce risk of CVC-related bloodstream infection.

Ultrasound guidance for nerve blocks has revolutionized LRA, and has become state of the art (www.nice.org.uk 2009). Precise identification of nerve structures minimizes risk of inadvertent vessel injury, intravascular injection and complicating hematoma. It improves block success, allows reducing LA dose and dose-related toxic effects $[16,17]$. Table 3 gives an overview of maximum recommended dose of LA.

As a consequence, use of ultrasound guidance for anesthesia preparations is strongly recommended as an important safety feature in vascular access surgery. 
Table 3. Maximum dose of $L A$ for regional nerve blocks in adults

\begin{tabular}{|c|c|c|c|c|c|}
\hline & Type & Main metabolism & $\begin{array}{l}\text { Onset of anesthesia } \\
\text { (depending on } \\
\text { injection site), min }\end{array}$ & $\begin{array}{l}\text { Duration } \\
\text { of action, } h\end{array}$ & Maximum dosage \\
\hline Lidocaine & amide & liver & $15-30$ & $\max .5$ & $\begin{array}{l}\text { max. } 4.5 \mathrm{mg} / \mathrm{kg} \text { body weight per single } \\
\text { injection; cumulative dose } 300 \mathrm{mg} / \text { day }\end{array}$ \\
\hline Bupivacaine & amide & liver $>$ kidney & $15-30$ & $4-6$ & cumulative dose max. 400 mg/day \\
\hline Mepivacaine & amide & liver & $15-30$ & $1.5-2$ & $\begin{array}{l}\text { max. } 5 \mathrm{mg} / \mathrm{kg} \text { body weight per single } \\
\text { injection; cumulative dose max. 1,000 } \\
\text { mg/day }\end{array}$ \\
\hline Ropivacaine & amide & liver/kidney & $10-25$ & $6-10$ & $\begin{array}{l}\text { max. } 250 \mathrm{mg} / \text { single injection; } \\
\text { cumulative dose } 800 \mathrm{mg} / \text { day }\end{array}$ \\
\hline
\end{tabular}

These data are based on Swissmedic information. Recommendations may vary between different countries due to local drug regulations. Rescue strategy: lipid rescue therapy can be used intravenously to absorb circulating LA.

Adequate training of ultrasound anatomy and needle navigation skills and dedicated equipment should be provided for and maintained by institutions and services involved.

\section{Intraoperative Safety Precautions}

In vascular access surgery, there is usually a choice between local, locoregional or GA. Although anesthesiological considerations apply, the type of anesthesia must be suitable for the planned surgery, should be accepted by the surgeon and also authorized by the patient with his/her written informed consent. Standard operating procedures should be established based on practice guidelines and scientific evidence.

During any type of anesthesia care, an ECG monitor, pulse oximetry, non-/ invasive blood pressure measurement and a reliable peripheral i.v. access are standard. If airway tools are employed, capnography is standard of care to prove correct placement of the artificial airway and the presence of respiration, gas exchange and circulation [18].

GA is suitable for all procedures in vascular access surgery patients. Renal insufficiency affects clinically relevant pharmacokinetics of some hypnotics, analgesics and relaxants.

Intravenous sedatives and nonopioid hypnotics (midazolam, propofol, etomidate, ketamine, dexmedetomidine) undergo mainly hepatic biotransformation to inactive metabolites. Their prolonged excretion owing to renal insufficiency is clinically not relevant. Nevertheless, in patients with renal failure a 
$25-50 \%$ dose reduction appears advisable due to alterations in blood volume, protein binding and pharmacodynamics.

Clinical pharmacology of synthetic opioid analgesics (fentanyl, sufentanil, remifentanil) is not substantially altered by renal failure. In contrast, morphine is a poor choice in patients with severe renal impairment, particularly when given repetitively. Morphine effects may be prolonged due to very slow elimination of active metabolites. Postoperative analgesic regimens should also avoid nonsteroidal anti-inflammatory drugs.

Among volatile anesthetics, isoflurane and desflurane are safe for use in patients with renal impairment and cardiovascular disease. These agents undergo minimal (hepatic) metabolism.

Nondepolarizing muscle relaxants are highly dependent on renal elimination if not inactivated otherwise. Degradation pathways of the relaxants atracurium or cisatracurium bypass renal function, making them preferable in renal insufficiency. Rocuronium has an increased elimination half-life in renal failure, but its action is swiftly and reliably terminated by i.v. administration of sugammadex.

Safe induction of GA for vascular access surgery should take specific risk constellations among these patients into account:

- In chronic renal failure, risks of pulmonary aspiration may be increased due to gastroparesis or abdominal distension from residual peritoneal dialysate.

- There is a significant risk of marked arterial hypotension, particularly on GA induction. Considerate selection and dose reduction of induction anesthetics, and titrated use of vasopressor drugs (ephedrine, noradrenaline or phenylephrine) will mitigate hypotensive episodes and prevent fluid overloading. Volemic effects of crystalloid solutions are limited to a short period of time, and fluid overloading may be associated with worse outcome [19]. Artificial colloid solutions appear obsolete due to their renal elimination. Alphaadrenoceptor agonists should be used conservatively, with the goal to normalize low systemic vascular resistance only. Unnecessary vasoconstriction may adversely affect outcome of peripheral vascular surgery.

LRA is ever gaining popularity for vascular access surgery due to its sympatholytic and venodilatory effect, overall cardiovascular stability and safety, and a potentially positive impact on surgical outcome [20]. The incidence of vasospasm and early thrombosis may be reduced [21]. The site of the regional block needs to be selected such as to adequately anesthetize the projected vascular access site (table 4). For vascular access surgery on the upper extremity, supraclavicular, infraclavicular or axillary nerve blocks are typically performed.

Despite the advantages of LRA, a survey of National Surgical Quality Improvement data (NSQIP; 2007-2010) still found a distribution of anesthesia 
Table 4. Covered areas of possible LRA procedures

\begin{tabular}{lllllll}
\hline \multirow{2}{*}{ Type of regional block } & \multicolumn{7}{l}{ Area of adequate surgical anesthesia } \\
\cline { 2 - 6 } & shoulder & upper arm & elbow & forearm & hand \\
\hline Interscalene nerve block & + & + (proximal) & - & - & - \\
Supraclavicular nerve block & - & + & + & + & + \\
Infraclavicular nerve block & - & + & + & + & + \\
Axillary nerve block & - & + (distal) & + & + & + \\
\hline
\end{tabular}

techniques for new arteriovenous fistula creation of 85\% GA, 3\% local anesthesia with monitored anesthetic care, and only 12\% LRA [22].

Compared to GA, an overall better safety profile of LRA has not been proven so far. Anesthesia planning in patients with ESRD and typical cardiovascular comorbidity must pay close attention to the coagulation system. When coagulation is compromised, regional nerve blocks are associated with a higher neurological complication rate than GA [13]. Ultrasound guidance to navigate nerve and vessel structures is highly recommended, with the aims to reduce accidental vessel injury and amount of LA required [18]. Still, this will not completely eliminate block-induced nerve lesions or hematoma formation.

Local anesthesia (LA) is a reasonable alternative if patients are compliant and cooperative, or when all other anesthesia options are either not applicable or increase risk more than LA. The sympathicolytic effect of LRA and its motor block cannot be reproduced using an LA technique. On the other hand, residual anticoagulant effects are less of an issue with LA than with LRA. For patients who are uncooperative or may become so during surgery (e.g. owing to substance dependency, paradoxical reactions, anxiety, delirium), LA is the least preferable option.

Basic monitoring standards apply as mentioned above. Depending on the patient's overall health status, it is advisable to combine surgical LA with monitored anesthesia care (MAC). Intraoperatively, MAC allows the anesthetist to diagnose and treat upcoming clinical problems adequately while the surgeon can concentrate on his work. When LA is managed without a professional dedicated to nonsurgical intraoperative patient care, risks from incomplete or discontinuous monitoring and inadequate sedation are inherent. In this field, most adverse outcomes arise from respiratory or cardiocirculatory depression. Therefore emergency equipment, medication and expertise to support or restore vital functions should be available in the procedure room, with advanced life support expert assistance available within 1-5 $\mathrm{min}$ [23]. 


\section{Intraoperative Environment}

During any operation, the ambient noise level should be minimized such to ensure safe communication between OR team members. This reduces distraction from their tasks as well as adverse effects (e.g. infections) [24]. Changes in patient condition or critical intraprocedural requirements (e.g. call for heparin) must be clearly communicated within the team in the closed-loop mode. Anybody who has important information should be allowed to speak up any time to inform the other team members.

The workplace should be organized ergonomically to facilitate the workflow of the OR team (fig. 1). Equipment should be arranged such as to allow adequate logistics for supplies, give access to the patient without breaking sterility, avoid tripwire incidents and cable disconnections, and to allow everybody a view to monitors. Urgent interventions should be possible without delay. Emergency equipment must be available and accessible at all times.

Perioperative normothermia avoids excessive sympathetic activation, shivering, coagulopathy and patient discomfort. Core temperature should be monitored continuously under GA. All patients should be kept normothermic with warming OR table mattresses or forced air warming systems. Patients with LRA or LA are clinically observed and asked whether they feel comfortable.

Allogenic blood product transfusion should be unnecessary in vascular access surgery with adequate preoperative preparation and surgical technique. Transfusion indications should be restrictive and take patients' preoperative chronic stable baseline into consideration. A valid transfusion trigger should combine hemoglobin concentration with the presence of clinical indicators of critical anemia or risks for critical end-organ ischemia (e.g. coronary or cerebrovascular disease [25-28]).

\section{Postoperative Care}

In the postoperative period, any patient emerging from GA or LRA should be observed in a postanesthesia care unit (PACU). Staff must be familiar with typical anesthesia- and surgery-related complications and postoperative surgical treatment. Postanesthetic and surgical orders (e.g. pain management, hemodynamic targets, antibiotics, anticoagulation, fluid regime, drains and dressings, positioning, chronic medication) must be documented in writing and actively communicated to PACU staff. Patency and function of a newly established vascular access as well as distal perfusion and sensorimotor function should be controlled regularly by clinical means and Doppler technique. After a regional nerve 


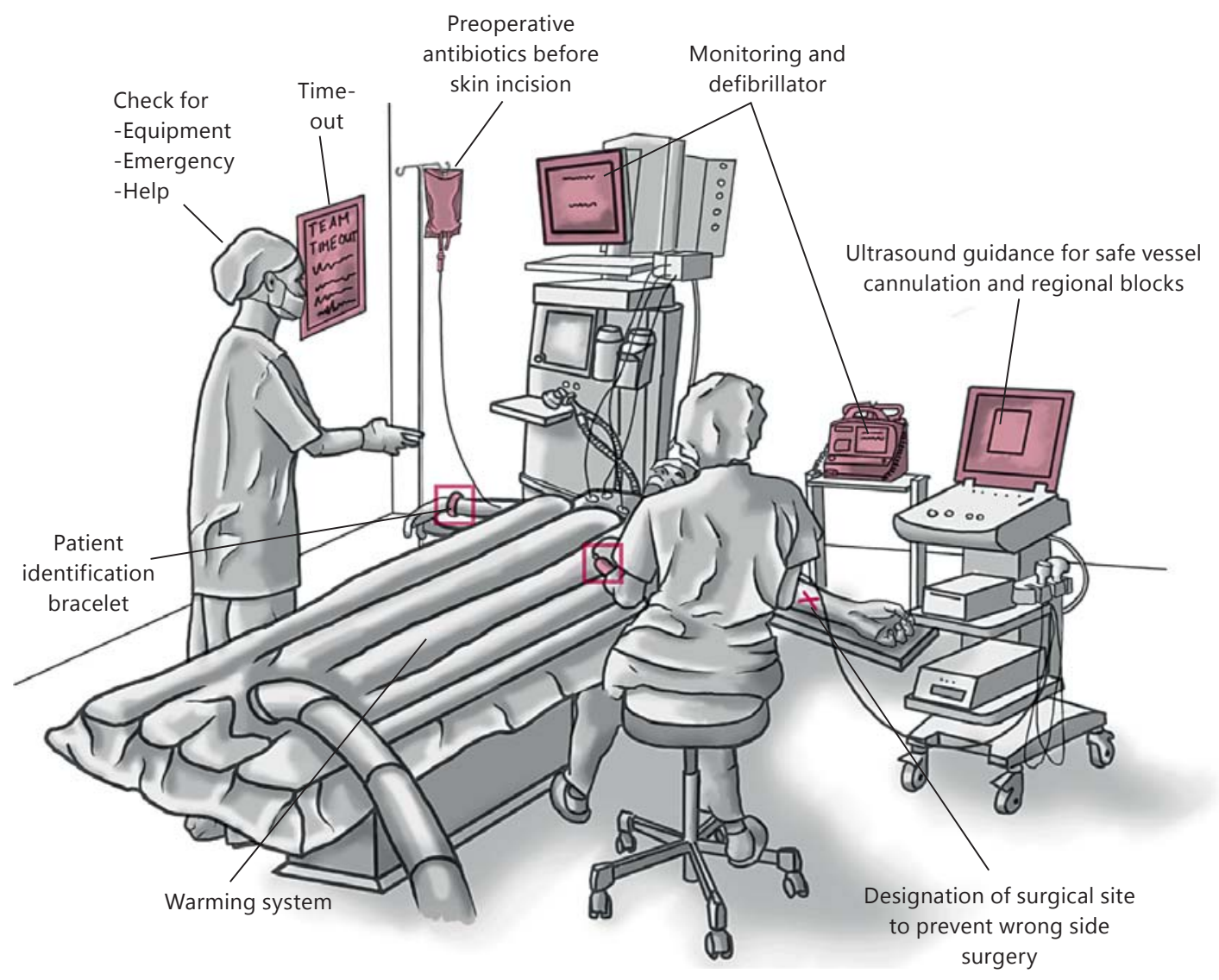

Fig. 1. OR setup and equipment for safe anesthesia performance in vascular access surgery.

block, at least the motor block should be regredient prior to discharge from PACU. Following GA, patients are released from the recovery area when awake and oriented, with vital functions stable, and with pain and postoperative nausea and vomiting under control.

Critical incident-reporting systems play an important role in identifying errors that are related to structural problems. Institutions can improve patient safety in vascular access surgery, as in any perioperative field, by improving OR and equipment ergonomics, by collective open-minded learning from each critical incident [29], by supporting training of technical and nontechnical skills (fig. 2) and critical incident management, and by promoting close interdisciplinary communication and good teamwork behavior [30]. 


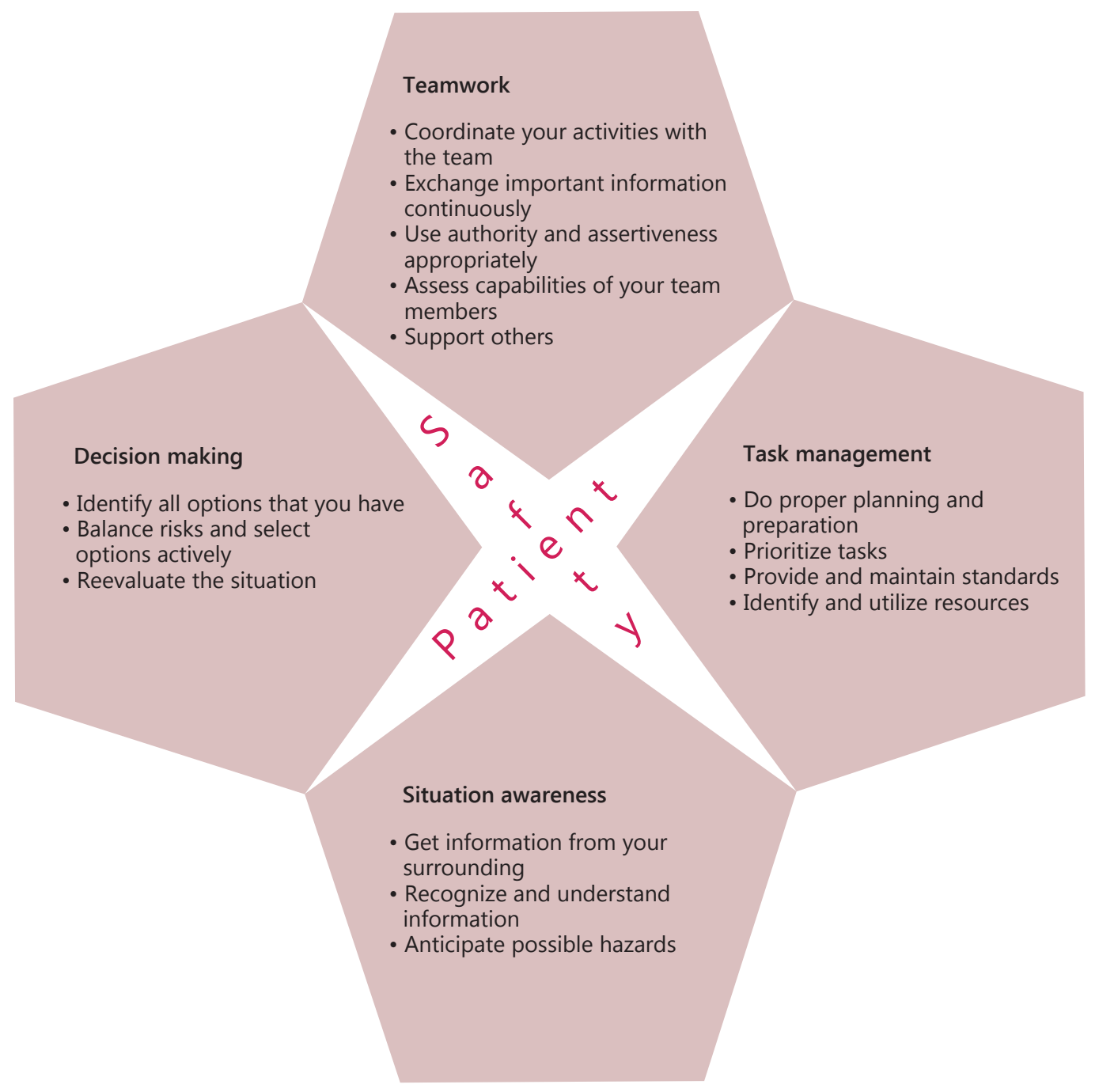

Fig. 2. Nontechnical skills that impact patient safety during the perioperative process [1].

\section{Disclosure Statement}

The authors have no conflicts of interest to declare. 


\section{References}

1 Rall M, Gaba DM: Human performance and patient safety; in Miller R (ed): Miller's Anesthesia, ed 7. Philadelphia, Churchhill Livingstone, 2009, pp 93-150.

-2 Kristensen SD, Knuuti J, Saraste A, Anker S, Botker HE, De Hert S, et al: 2014 ESC/ESA Guidelines on non-cardiac surgery: cardiovascular assessment and management: The Joint Task Force on non-cardiac surgery: cardiovascular assessment and management of the European Society of Cardiology (ESC) and the European Society of Anaesthesiology (ESA). Eur Heart J 2014;35:2383-2431.

3 American Society of Anesthesiologists: ASA Physical Status Classification System. https:// www.asahq.org.

4 De Hert S, Imberger G, Carlisle J, Diemunsch P, Fritsch G, Moppett I, et al: Preoperative evaluation of the adult patient undergoing non-cardiac surgery: guidelines from the European Society of Anaesthesiology. Eur J Anaesthesiol 2011;28:684-722.

5 Glance LG, Lustik SJ, Hannan EL, Osler TM, Mukamel DB, Qian F, et al: The Surgical Mortality Probability Model: derivation and validation of a simple risk prediction rule for noncardiac surgery. Ann Surg 2012;255:696702.

6 Poldermans D, Bax JJ, Boersma E, De Hert S, Eeckhout E, Fowkes G, et al: Guidelines for pre-operative cardiac risk assessment and perioperative cardiac management in noncardiac surgery. Eur Heart J 2009;30:27692812.

7 Lumb A, Biercamp C: Chronic obstructive pulmonary disease and anaesthesia. Contin Educ Anaesth Crit Care Pain 2014;14:1-5.

8 Gogarten W, Vandermeulen E, Van Aken H, Kozek S, Llau JV, Samama CM: Regional anaesthesia and antithrombotic agents: recommendations of the European Society of Anaesthesiology. Eur J Anaesthesiol 2010;27: 999-1015.

>9 Smith I, Kranke P, Murat I, Smith A, O’Sullivan G, Soreide E, et al: Perioperative fasting in adults and children: guidelines from the European Society of Anaesthesiology. Eur J Anaesthesiol 2011;28:556-569.

10 WHO's patient-safety checklist for surgery. Lancet 2008;372:1.
11 Hubalewska A, Stompor T, Placzkiewicz E, Staszczak A, Huszno B, Sulowicz W, et al: Evaluation of gastric emptying in patients with chronic renal failure on continuous ambulatory peritoneal dialysis using 99mTc-solid meal. Nucl Med Rev Cent East Eur 2004;7: 27-30.

12 Soar J, Perkins GD, Abbas G, Alfonzo A, Barelli A, Bierens JJ, et al: European Resuscitation Council Guidelines for Resuscitation 2010 Section 8. Cardiac arrest in special circumstances: electrolyte abnormalities, poisoning, drowning, accidental hypothermia, hyperthermia, asthma, anaphylaxis, cardiac surgery, trauma, pregnancy, electrocution. Resuscitation 2010;81:1400-1433.

13 Weinberg GL: Lipid emulsion infusion: resuscitation for local anesthetic and other drug overdose. Anesthesiology 2012;117:180-187.

14 Santoro D, Benedetto F, Mondello P, Pipito N, Barilla D, Spinelli F, et al: Vascular access for hemodialysis: current perspectives. Int J Nephrol Renovasc Dis 2014;7:281-294.

15 Crossley GH, Poole JE, Rozner MA, Asirvatham SJ, Cheng A, Chung MK, et al: The Heart Rhythm Society (HRS)/American Society of Anesthesiologists (ASA) Expert Consensus Statement on the perioperative management of patients with implantable defibrillators, pacemakers and arrhythmia monitors: facilities and patient management this document was developed as a joint project with the American Society of Anesthesiologists (ASA), and in collaboration with the American Heart Association (AHA), and the Society of Thoracic Surgeons (STS). Heart Rhythm 2011;8:1114-1154.

16 Eichenberger U, Stockli S, Marhofer P, Huber G, Willimann P, Kettner SC, et al: Minimal local anesthetic volume for peripheral nerve block: a new ultrasound-guided, nerve dimension-based method. Reg Anesth Pain Med 2009;34:242-246.

17 Marhofer P, Eichenberger U, Stockli S, Huber G, Kapral S, Curatolo M, et al: Ultrasonographic guided axillary plexus blocks with low volumes of local anaesthetics: a crossover volunteer study. Anaesthesia 2010;65:266271.

18 Buhre W, Rossaint R: Perioperative management and monitoring in anaesthesia. Lancet 2003;362:1839-1846. 
19 Doherty M, Buggy DJ: Intraoperative fluids: how much is too much? Br J Anaesth 2012; 109:69-79.

20 Malinzak EB, Gan TJ: Regional anesthesia for vascular access surgery. Anesth Analg 2009; 109:976-980.

21 Shemesh D, Raikhinstein Y, Orkin D, Goldin I, Olsha O: Anesthesia for vascular access surgery. J Vasc Access 2014;15(suppl 7):S38S44.

22 Siracuse JJ, Gill HL, Parrack I, Huang ZS, Schneider DB, Connolly PH, et al: Variability in anesthetic considerations for arteriovenous fistula creation. J Vasc Access 2014, Epub ahead of print.

23 American Society of Anesthesiologists Task Force on Sedation and Analgesia by Non-Anesthesiologists: Practice guidelines for sedation and analgesia by non-anesthesiologists. Anesthesiology 2002;96:1004-1017.

24 Kurmann A, Peter M, Tschan F, Muhlemann K, Candinas D, Beldi G: Adverse effect of noise in the operating theatre on surgical-site infection. Br J Surg 2011;98:1021-1025.

25 Carson JL, Grossman BJ, Kleinman S, Tinmouth AT, Marques MB, Fung MK, et al: Red blood cell transfusion: a clinical practice guideline from the AABB*. Ann Intern Med 2012;157:49-58.
26 Carson JL, Duff A, Poses RM, Berlin JA, Spence RK, Trout R, et al: Effect of anaemia and cardiovascular disease on surgical mortality and morbidity. Lancet 1996;348:10551060.

27 Spahn DR, Moch H, Hofmann A, Isbister JP: Patient blood management: the pragmatic solution for the problems with blood transfusions. Anesthesiology 2008;109:951-953.

28 Kozek-Langenecker SA, Afshari A, Albaladejo P, Santullano CA, De Robertis E, Filipescu DC, et al: Management of severe perioperative bleeding: guidelines from the European Society of Anaesthesiology. Eur J Anaesthesiol 2013;30:270-382.

29 Mahajan RP: Critical incident reporting and learning. Br J Anaesthesia 2010;105:69-75.

30 Wahr JA, Prager RL, Abernathy JH 3rd, Martinez EA, Salas E, Seifert PC, et al: Patient safety in the cardiac operating room: human factors and teamwork: a scientific statement from the American Heart Association. Circulation 2013;128:1139-1169.

Balthasar Eberle, MD

University Department for Anesthesiology and Pain Therapy

Inselspital, Bern University Hospital

Freiburgstrasse, $\mathrm{CH}-3010$ Bern (Switzerland)

E-Mail balthasar.eberle@insel.ch 